\title{
Soft Chemical Synthesis of Nickel-Zinc-Cobalt- Ferrite Nanoparticles and their Structural, Morphological and Magnetic Study at Room Temperature
}

\author{
D. Parajuli, V. K. Vagolu, K. Chandramoli, \\ N. Murali, K. Samatha
}

Journal of Nepal Physical Society

Volume 7, Issue 4, December 2021

ISSN: 2392-473X (Print), 2738-9537 (Online)

Editors:

Dr. Binod Adhikari

Dr. Bhawani Joshi

Dr. Manoj Kumar Yadav

Dr. Krishna Rai

Dr. Rajendra Prasad Adhikari

Mr. Kiran Pudasainee

JNPS, 7 (4), 14-18 (2021)

DOI: http://doi.org/10.3126/jnphyssoc.v7i4.42926

Published by:

Nepal Physical Society

P.O. Box: 2934

Tri-Chandra Campus

Kathmandu, Nepal

Email: nps.editor@gmail.com

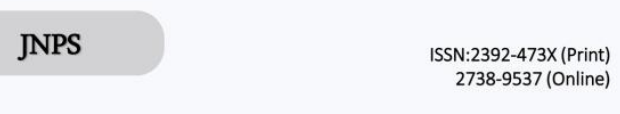

Journal of

Nepal Physical Society

Volume 7, Issue 4, December 2021

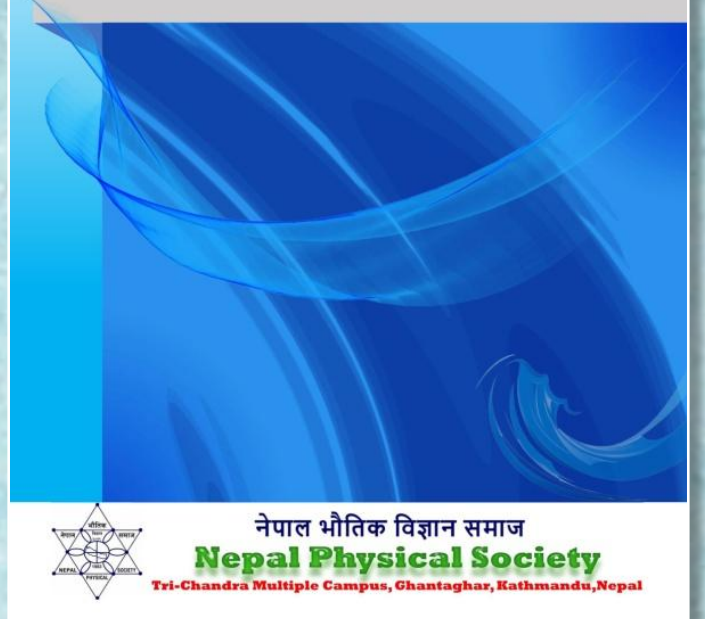




\title{
Soft Chemical Synthesis of Nickel-Zinc-Cobalt-Ferrite Nanoparticles and their Structural, Morphological and Magnetic Study at Room Temperature
}

\author{
D. Parajuli ${ }^{1,2, ~ *}$, V. K. Vagolu ${ }^{3}$, K. Chandramoli ${ }^{4}$, N. Murali ${ }^{4}$, K. Samatha ${ }^{3}$ \\ ${ }^{1}$ Research Center for Applied Science and Technology, Tribhuvan University, Kirtipur, Nepal \\ ${ }^{2}$ Department of Physics, Tri-Chandra Multiple Campus, Kathmandu, Nepal \\ ${ }^{3}$ Department of Physics, Andhra University, Visakhapatnam-530003, India \\ ${ }^{4}$ Department of Engineering Physics, AUCE, Andhra University, Visakhapatnam-530003, India \\ *Corresponding Email: deepenparaj@gmail.com
}

Received: 14th November, 2021; Revised: 17th December, 2021; Accepted: 26th December, 2021

\begin{abstract}
The cobalt substituted Nickel-Zinc ferrites with the composition $\mathrm{Ni}_{0.95-\mathrm{x}} \mathrm{Zn}_{0.05} \mathrm{Co}_{\mathrm{x}} \mathrm{Fe}_{2} \mathrm{O}_{4}$, for $\mathrm{x}=$ $0.01,0.02,0.03,0.04,0.05$ and 0.06 were synthesized by the soft chemical route method and were found to have cubic system of ferrimagnetic spinel using XRD. The grain sizes decreases significantly with the cobalt content $(\mathrm{x})$ and are $1.62-1.36 \mathrm{~nm}$ for $\mathrm{x}=0.01$ to 0.06 which are small enough to produce appropriate high density recording media. The particle size is found to be in the range 29-22 $\mathrm{nm}$ with the help of SEM. Their magnetic properties determined with VSM show the dependency on the exchange interaction due to the cobalt substitution between the metal ions of tetra and octahedral sites. Increasing grain size and decreasing porosity increases the magnetic saturation.
\end{abstract}

Keywords: Soft chemical route, ferrimagnetic spinel, XRD, SEM, VSM.

\section{INTRODUCTION}

Ferrite nanoparticles have attracted a lot of attention from a long ago due to their technological importance in high density magnetic storage, electronic and microwave devices, communication devices, sensors and the phenomena like ferrofluidicity, drug delivery, separable catalysts etc. driven by magnetic properties. During the course of investigations with various nanoferrites, the doping of cobalt into various ferrites has been found to be interesting and of high importance due to the drastic changes in their properties. In the nickel-zinc ferrite systems, the Co substitution is widely in practice for the absorption of electromagnetic waves in high frequency region [1] like, switching magnets, pulse compressors [2, 3], antenna rods for radios [4], transformers, reactor cores, etc. Most of the ferromagnetic core materials are designed with $\mathrm{Ni}-$ $\mathrm{Co}-\mathrm{Zn}$, Ni-Cu-Zn, Ni-Cd-Zn, Co-Ni-Zn ferrites [59]. The higher hardness, resistivity and stability are achieved through the polycrystalline ferrites. There is a great demand for the improvement of devices which basically work on the effective functionalizing of soft magnetic material. Tremendous work is under progress across the globe in preparing super paramagnetic material on one hand and for the material suitable for high-frequency applications. As the substitution cobalt influences the properties of mixed Ni-Zn ferrites, studies by changing to low sintering temperatures are suggested. Study on the magnetic properties at low temperatures and at different field strengths gives the complete understanding of exchange interactions. This helps in explaining the applications of the materials at different frequencies. Dielectric studies will give the correct cation distribution. This study could focus on magnetic, dielectric and electric properties of cobalt substituted nickel zinc ferrites.

\section{EXPERIMENTAL PROCEDURE}

The soft chemical route method is used for the preparation of the nanoferrites $\mathrm{Ni}_{0.95}$ ${ }_{x} \mathrm{Zn}_{0.05} \mathrm{Co}_{\mathrm{x}} \mathrm{Fe}_{2} \mathrm{O}_{4}$ of appropriate stoichiometry [1012]. They are then calcined for the oxide preparation [13]. The fine particles with lower solubility and lower decomposing temperature less than $873 \mathrm{~K}$, of citrate, made them appropriate as our precursors [14]. The AR grade aqueous solution of 
Nickel, Zinc and Cobalt nitrates in appropriate ratio is mixed with ferric citrate in 1:1 molar ratio and made it neutral by the addition of ammonium hydroxide. The solution was dried over the 10 to 12 hours with the addition of ethylene glycol. The puffy and porous dry gel was formed. The gel is then self-ignited into fine powder which then sintered at $800^{\circ} \mathrm{C}$ for 2 hours for the removal of remaining carbon. The pallets of $12 \mathrm{~mm}$ diameter and $2 \mathrm{~mm}$ thickness were prepared with the use of hydraulic press of 5 tons and sintered at 900$1200^{\circ} \mathrm{C}$ for two hours in air. Commercial vibrating sample magnetometer (VSM) model BHV-50 of Riken Denshi Co. Ltd. Japan was used for the measurement of sample's magnetization.

\section{RESULT AND DISCUSSION \\ Structural Properties- XRD Study}

The XRD gives the structural properties of the $\mathrm{Ni}_{0.95-\mathrm{x}} \mathrm{Zn}_{0.05} \mathrm{Co}_{\mathrm{x}} \mathrm{Fe}_{2} \mathrm{O}_{4} \quad$ (NZCF) samples which were calcined at $800^{\circ} \mathrm{C}$. The XRD patterns of Nickel and Zinc ferrites are shown in Figure 1 in which show X-ray diffraction patterns of Zinc ferrite. JCPDS file No.: 08-0234 was matched with the structure observed with the help of the peak position and relative intensity of all diffraction peaks. They have pure cubic spinel structure having peaks (111), (220), (311), (222), (400), (422), (511) and (440) of the respective planes [15].

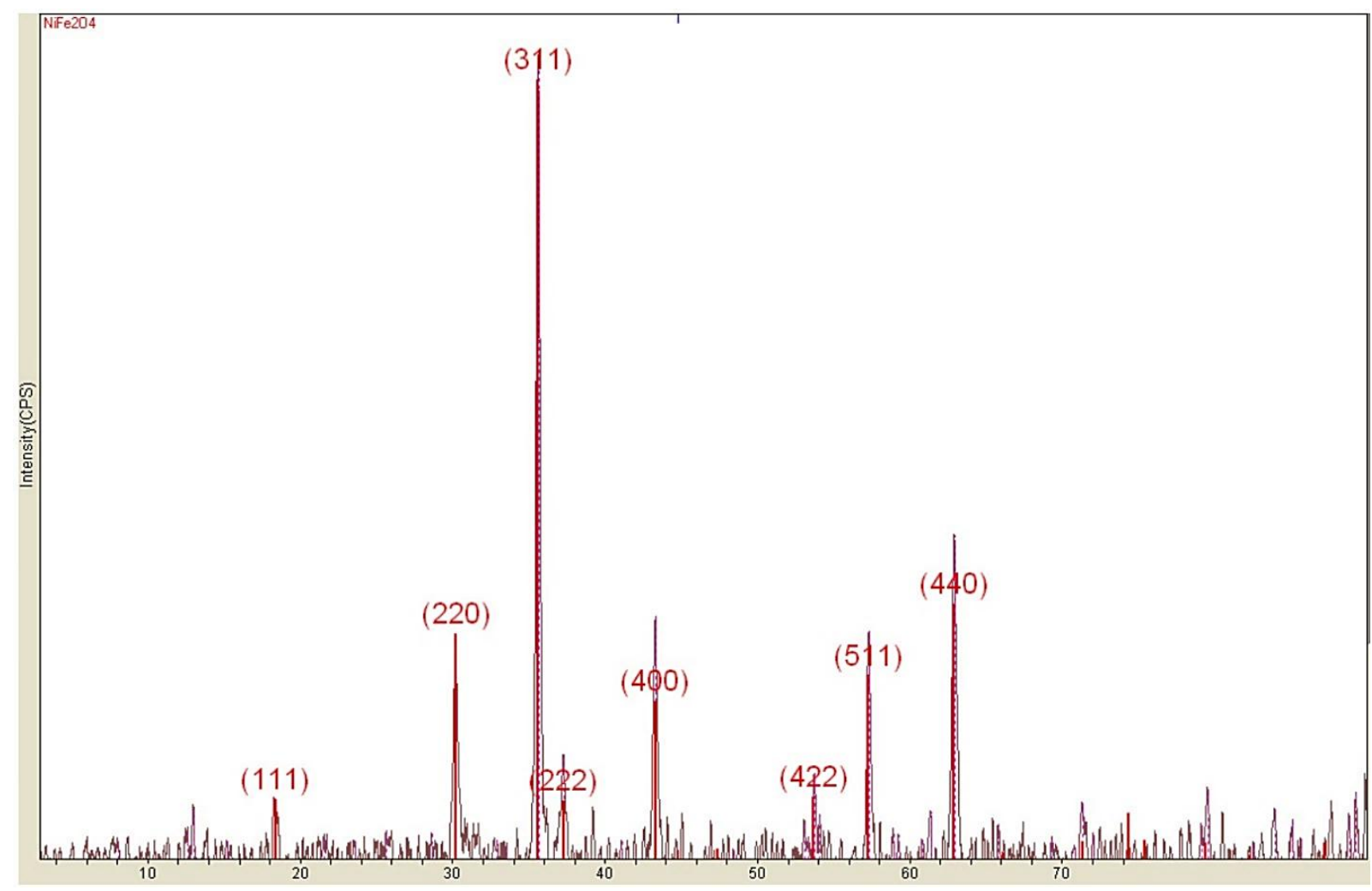

Fig. 1: X-ray diffraction pattern of a Nickel ferrite crystal

\section{Surface Morphology-FESEM study:}

The SEM micrographs of cobalt substituted Ni-Zn ferrite samples containing Cobalt content of $\mathrm{x}=$ $0.01,0.02,0.03,0.04,0.05,0.06$ are shown in Figure 2 (a-f) scaled $20 \mu \mathrm{m}, 10 \mu \mathrm{m}, 10 \mu \mathrm{m}, 5 \mu \mathrm{m}, 2$ $\mu \mathrm{m}, 2 \mu \mathrm{m}$ respectively. The line intercept method was used for the average grain size calculation and is found to be in the range $1.62-1.36 \mathrm{~nm}$. It is clear from the figures that the particles have well-defined shape and boundaries. The Scherer's formula is accurate enough for the crystallite size calculation which are decreased with the cobalt addition as listed in Tables1. The grain sizes decreases significantly with the cobalt content $(\mathrm{x})$ and are in between 30 to $50 \mathrm{~nm}$ for $\mathrm{x}=0.01$ to 0.06 . They are small enough to produce appropriate high density recording media for daily uses. The particle size is found to be in the range $29-22 \mathrm{~nm}$ with the help of SEM and are in the supports their crystalline behavior shown by the XRD data. 
Table 1: Structural variation of NZCF

\begin{tabular}{c|c|c|c|c|c|c|c}
\hline S. N. & Sample & $\begin{array}{c}\text { Lattice } \\
\text { parameter }\end{array}$ & $\begin{array}{c}\text { Density } \\
(\mathbf{\%})\end{array}$ & FWHM & $\begin{array}{c}\text { Porosity } \\
(\boldsymbol{\%})\end{array}$ & $\begin{array}{c}\text { Grain size } \\
(\mathbf{D}) \mathbf{~ n m}\end{array}$ & $\begin{array}{c}\text { Particle } \\
\text { size } \mathbf{~ n m}\end{array}$ \\
\hline 1. & 0.01 & 8.387 & 92.5 & 0.281 & 7.4 & 1.62 & 29 \\
2. & 0.02 & 8.389 & 91.9 & 0.272 & 7.3 & 1.58 & 27 \\
3. & 0.03 & 8.392 & 91.7 & 0.228 & 6.8 & 1.46 & 23 \\
4. & 0.04 & 8.395 & 92.2 & 0.260 & 8.0 & 1.41 & 22 \\
5. & 0.05 & 8.396 & 92.5 & 0.249 & 8.3 & 1.39 & 22 \\
6. & 0.06 & 8.398 & 93.5 & 0.280 & 7.7 & 1.36 & 22 \\
\hline
\end{tabular}

This analysis involving the above spectral data shows that spinel structures have been obtained by this chemical route at lower temperatures. This method is time saving when compared to the time consuming

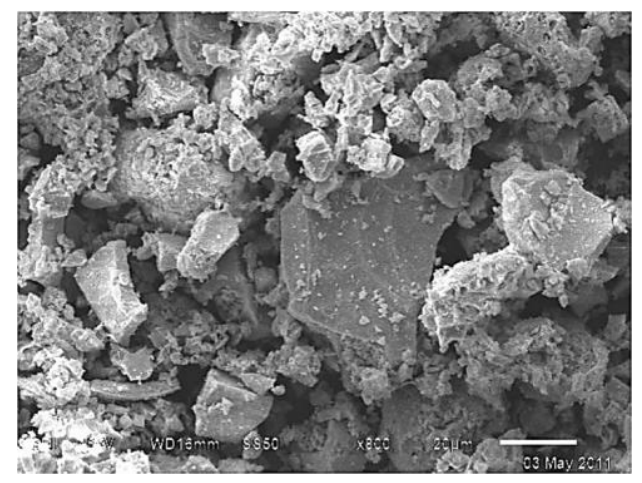

(a) $\mathrm{x}=0.01$

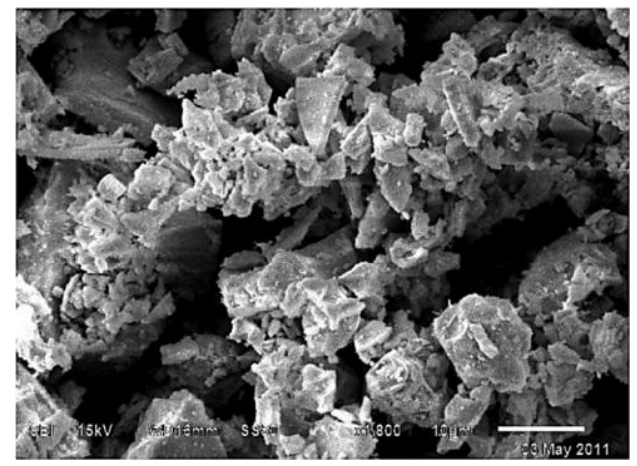

(c) $\mathrm{x}=0.03$

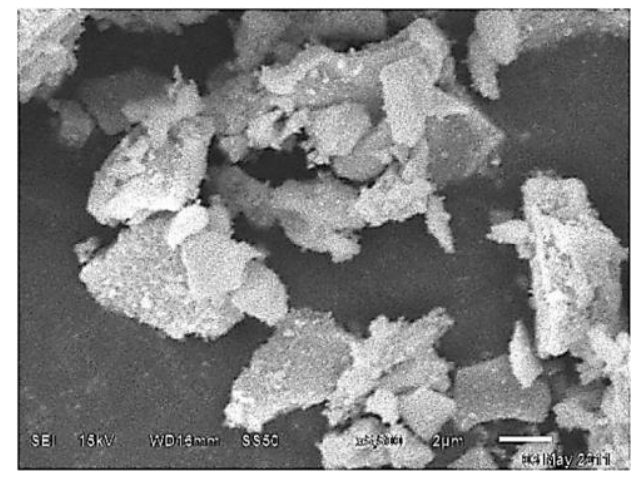

(e) $x=0.05$ and tiresome other processes involved in the manufacturing of nanoferrites. For other methods like citrate precursor, larger sintering temperature is needed however fine particles are obtained.

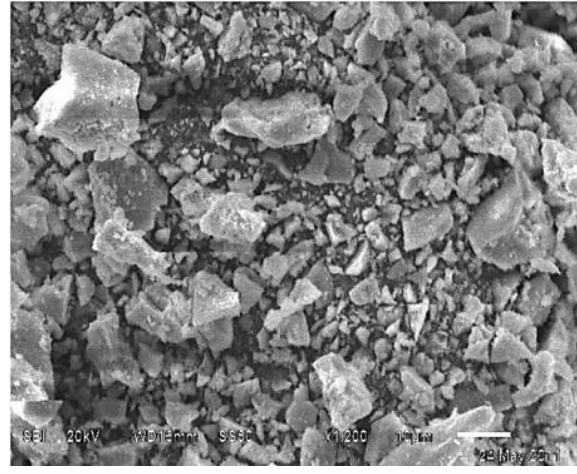

(b) $x=0.02$

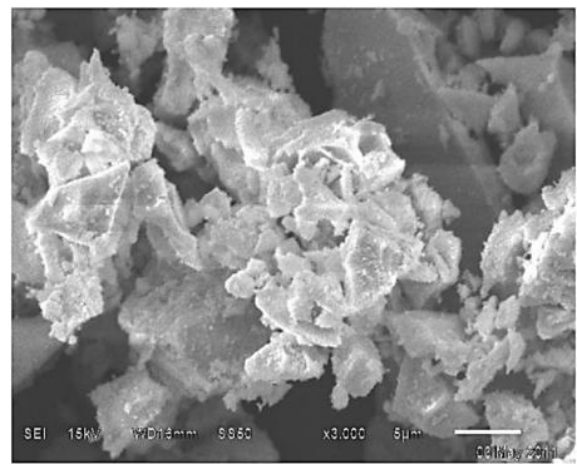

(d) $x=0.04$

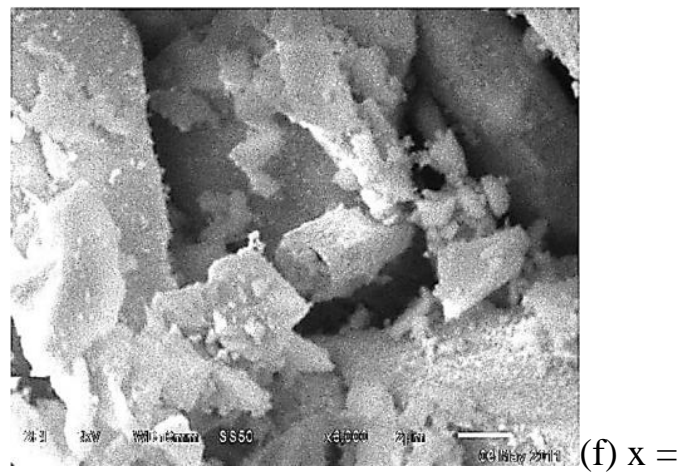

0.06

Fig. 2: Micrographs of powder observed by SEM for $\mathrm{x}=$ (a) 0.01 (b) 0.02 (c) 0.03 (d) 0.04 (e) 0.05 (f) 0.06 


\section{Magnetic properties-VSM Study}

A maximum field of $10 \mathrm{kG}$ (10000 gauss) was used at room temperature to find the specific magnetization (Ms), remnant magnetization (Mr) and coercive field $(\mathrm{Hc})$ of NZCF which depends especially on cobalt content as shown in Figure 3(a) to 3(f) respectively. The Ms first decrease from $\mathrm{x}=$ 0.01 to $x=0.03$, then increase for $x=0.04$ and again is very low for $\mathrm{x}=0.05$ and $\mathrm{x}=0.06$ respectively. The reduction is due to the cation interaction among the cations in A and B interstitial sites, higher contribution by orbital motion of $\mathrm{Co}^{2+}$ ions for inducing magnetic moment and hence anisotropy. Oxygen ions are nonmagnetic which separate two magnetic ions in ferrites. This lead to the super-exchange interaction among the magnetic ions with neighboring nonmagnetic ions. There is a surface spin disorder due to impurity in place of oxygen at the surface which breaks the superexchange bonds among the magnetic cations [16]. The ferrite is not mixed. Instead the value of Ms is decreased $[17,1]$.
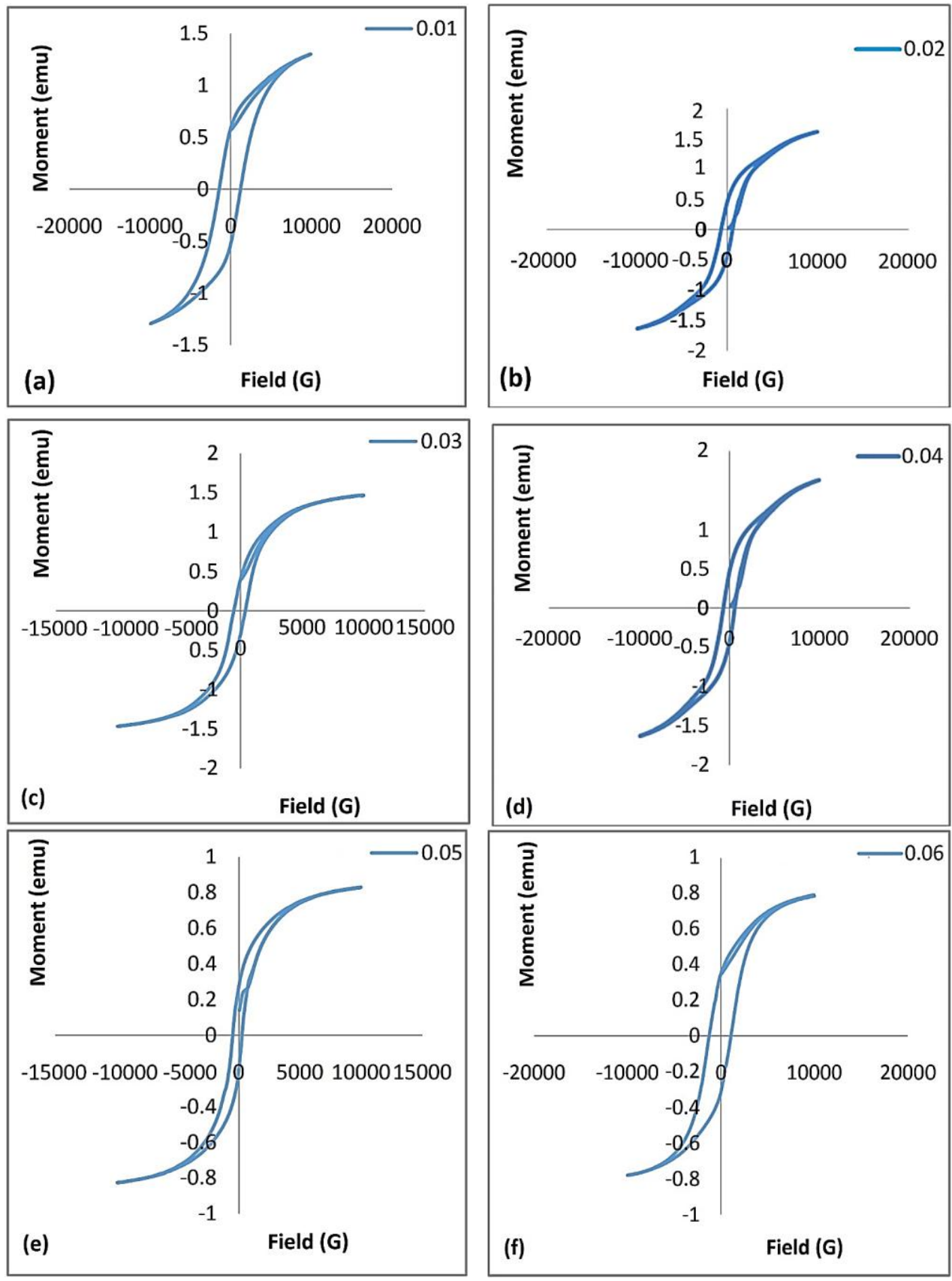

Fig. 3: NZCF with concentration (x) valued a) 0.01 b) 0.02 c) 0.03 d) 0.04 e) 0.05 f) 0.06 
The coercivity and hence the magnetic anisotropy is also increased with the cobalt content as shown in Figure 3 for NZCF. The magneto-crystalline anisotropy constant depends on the coercive field (Hc) which is due to the spin orbit coupling created by the $\mathrm{Co}^{2+}$ ions entering into the lattice. This leads to decrease in the domain wall. This overall effect is due to the super-paramagnetic natured particles. Another factor reducing the $\mathrm{Hc}$ is its microstructure. The microstructure composed of grains acting as magnetic dipole and results the magnetic saturation. However, the defects or the pores embedded in the structure reduces the magnetization [2]. In totality, increasing grain size and decreasing porosity increases the magnetic saturation.

\section{CONCLUSIONS}

The soft chemical route was followed for the preparation of the nanocrystalline cobalt substituted $\mathrm{Ni}-\mathrm{Zn}$ ferrites, $\mathrm{Ni}_{0.95-\mathrm{x}} \mathrm{Zn}_{0.05} \mathrm{Co}_{\mathrm{x}} \mathrm{Fe}_{2} \mathrm{O}_{4}$ for $\mathrm{x}=0.01,0.02,0.03,0.04,0.05$ and 0.06. XRD shows the cubic system with ferrimagnetic spinel structure of the samples. It is further observed that the lattice parameter a $\left({ }^{\circ} \mathrm{A}\right)$ increases with the addition of $\mathrm{Co}^{2+}$ ions in the $\mathrm{Ni}-\mathrm{Zn}$ ferrite matrix. The Ms first decrease from $x=0.01$ to $\mathrm{x}=0.03$, then increase for $\mathrm{x}=0.04$ and again is very low for $\mathrm{x}=0.05$ and $\mathrm{x}=0.06$ respectively. Co content rises grain size, magnetic moment, anisotropy, orbital motion, exchange interaction, super-exchange interaction, and coercive force, with super-paramagnetic nature. Increasing grain size and decreasing porosity increases the magnetic saturation. The parameters obtained are sufficient to produce high density recording media and many others for daily uses.

\section{REFERENCES}

1. Kang, D. H.; Shin, J. Y. and Oh; J. H. Proc. 6th Int. Conf. on Ferrites (Tokyo and Kyoto, Japan) (1992).

2. Shinde, R. S.; Bhasin, H. K. and Karmarkar, M. G. 7th Int.Conf. on Ferrites (Bordeaux, France); J. Phys. IV France 7 C1-149-50 (1997).

3. Shinde, R. S.; Pareek, P. and Yadav, R. R. Proc. APAC (Gyeongju, Korea), p 699 (2004).

4. Bradley, F. N. Materials for Magnetic Functions (New York: Hayden) (1971).

5. Parajuli, D. and Samatha, K. The Journal of Physical Science, BIBECHANA, 18(1): 128-133 (2020).

6. Parajuli, D.; Samatha, K. The Journal of Physical Science, BIBECHANA, 18(2): 80-86 (2021).

7. Parajuli, D.; Vemuri, R.; Suryanarayana, B.; Rao, P. N.; Murali, N.; et. al. Results in Physics, 23: 103947 (2021).

8. Parajuli, D.; Murali, N. and Samatha, K. JNPS, 7(2): 24-32 (2021).

9. Parajuli, D., Taddesse, P., Murali, N., Samatha, K. Appl. Phys. A 128: 58 (2022).

10. Stuijts, A. L. Proc. Brit. Ceram. Soc. 2, 72 (1964).

11. Reignon, P. J. L. So. Ceram. 4, 169 (1968).

12. Burke, J. E. -Kinetics of High Temperature Processes Clarendon Press, New York, 109 (1959).

13. Paulus, M. Preparative Methods in Solid State Chemistry (ed) O Hagenmuller (New York: Academic), p 487 (1972).

14. Longo, J. M.; Horowitz, H. S.; Clevenna, L. R.; Holt, S. L.; Milstein, J. L. and Robbins (ed), M. Solid State Chemistry-A, (1986).

15. Cullity, B. D. Elements of X-ray diffraction (Addison Wesley Publication, Reading, (1956).

16. Contemporary Overview (Advances in Chemistry Series) (Washington, DC: American Chemical Society) p 139 SchueleW J J. Phys. Chem. 63: 83 (1959).

17. Klienert, P. and Funke, A. J. Chem. 1/5 155, 9. (1961). R.D. Waldron, Phys. Rev. 99, 1727 (1955). 